\title{
Luz à primeira vista: um programa de atividades para o ensino de óptica a partir de cores
}

\author{
Light at first sight: a program of activities to teach optics using colors
}

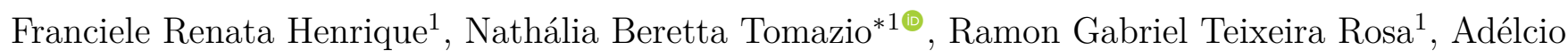
Marques de Souza ${ }^{2}$, Camila de Paula D'Almeida ${ }^{1}$, Lucas Fiocco Sciuti ${ }^{1}$, Marlon Rodrigues Garcia ${ }^{2}$, Leonardo De Boni ${ }^{1}$
\end{abstract}

\author{
${ }^{1}$ Universidade de São Paulo, Instituto de Física de São Carlos, São Carlos, SP, Brasil \\ ${ }^{2}$ Universidade de São Paulo, Escola de Engenharia de São Carlos, São Carlos, SP, Brasil
}

Recebido em 01 de Agosto, 2018. Revisado em 16 de Outubro, 2018. Aceito em 28 de Novembro, 2018.

\begin{abstract}
A implementação de atividades práticas que envolvam cores constitui uma estratégia poderosa para estimular o interesse de crianças e adolescentes para a Ciência. Devido ao seu forte apelo visual e presença no cotidiano, as cores despertam a curiosidade dos estudantes e propiciam o aprendizado de conceitos fundamentais no campo da Óptica, tais como reflexão, transmissão e refração. Nesse trabalho, descrevemos um programa de atividades desenvolvido para ensinar conceitos de Óptica presentes na formação de cores a partir de materiais simples, baratos e acessíveis. Através de demonstrações abertas e discussões autônomas por parte dos estudantes, elucidamos o processo de formação de cores por reflexão e transmissão, bem como a razão pela qual se pode visualizar objetos incolores. As atividades aqui descritas foram apresentadas num evento de divulgação científica direcionado a crianças e adolescentes com idade entre 8 e 17 anos.
\end{abstract}

Palavras-chave: Ensino de Óptica, cores.

The implementation of practical activities that involve colors consists in a powerful strategy to stimulate the children and teenagers' interest in Science. Due to its strong visual appeal and presence in everyday life, colors spark students' curiosity and allow the learning of fundamental concepts in Optics, such as reflection, transmission and refraction. In this work, we describe a program of activities developed to teach concepts of Optics present in color formation by means of simple, cheap and accessible materials. Through open demonstrations and the students' autonomous discussion, we clarify the process of color formation by reflection and transmission, as well as the reason by which we can observe colorless objects. The activities described here were presented in a science outreach event directed to children and teenagers with ages ranging from 8 to 17 years old.

Keywords: Optics teaching, colors.

\section{Introdução}

Vários métodos têm sido propostos para o ensino de ciências na educação básica, dentre eles destacam-se atividades com métodos de verificação de modelos teóricos, observação investigativa, experimentação investigativa e demonstração. Essa última ainda pode ser dividida em demonstrações fechadas, com caráter puramente expositivo por parte do professor, e demonstrações abertas, centradas nos estudantes.[1] As demonstrações abertas têm por objetivo tornar o estudante um agente ativo, corresponsável pelo processo de aprendizagem. Para isto, as aulas são divididas em pequenas séries de apresentações orais por parte do professor, com breves instruções e questionamentos acerca do objeto de estudo, seguidas por atividades a serem realizadas pelos estudantes.

O uso de atividades experimentais para a realização de demonstrações abertas tem sido muito incentivado por

*Endereço de correspondência: nathaliatomazio@gmail.com especialistas em educação para estimular a participação e despertar o interesse dos estudantes.[2,3] A combinação de uma metodologia de ensino por demonstração a experimentos com elementos próximos ao cotidiano, torna os estudantes mais autônomos, permitindo que eles próprios desenvolvam hipóteses sem depender de fórmulas prontas ou orientações diretas por parte dos professores. Não se trata de fazer novas descobertas científicas ou mesmo formar pesquisadores, mas sim promover uma interação prática entre os estudantes, os professores e os objetos de estudo.[4,5]

Nesse trabalho descrevemos um conjunto de atividades de demonstração aberta desenvolvido para elucidar conceitos fundamentas de Óptica a partir do processo de formação de cores em objetos opacos e transparentes. Por seu caráter visual e sua presença no cotidiano, as cores estimulam o interesse dos estudantes, facilitando assim o aprendizado de conceitos como reflexão, transmissão e refração. As atividades aqui descritas fazem parte de 
uma iniciativa de divulgação científica do USP - IFSC OSA Student Chapter realizada na escola de idiomas The Four, em São Carlos (SP), para estudantes com idades entre oito e dezessete anos em turmas de 5 a 15 alunos, totalizando aproximadamente 100 alunos. O USP - IFSC OSA Student Chapter é uma organização de estudantes da Universidade de São Paulo - Campus São Carlos, vinculada à $O S A$ - The Optical Society, que tem por finalidade o desenvolvimento profissional de estudantes de graduação e pós-graduação em áreas relacionadas à Óptica assim como a disseminação do conhecimento nessa área a partir de atividades de divulgação científica.

O artigo está organizado da seguinte forma: na seção 1 introduzimos as definições de objetos opacos e transparentes e os conceitos envolvidos no processo de formação de cores, na seção 2 descrevemos os materiais utilizados e o programa de atividades que desenvolvemos para o evento de divulgação científica e por fim, na seção 3 apresentamos as considerações finais desse trabalho.

\section{Fundamentação Teórica}

\subsection{Definições}

Os meios materiais podem ser classificados de acordo com a forma como interagem com a luz. Meios opacos não permitem a passagem de luz por eles. Ao incidir sobre objetos opacos, a luz é completamente absorvida ou refletida. Dessa forma, não conseguimos ver através de um objeto opaco. São exemplos de objetos opacos: uma cadeira de madeira, um livro, uma pedra. Os meios transparentes permitem que a luz passe por eles, fazendo que possamos enxergar através deles. São exemplos de objetos transparentes: um copo de vidro, as lentes de um óculos e uma gota d'água. Os meios translúcidos, que não serão abordados nesse trabalho, são aqueles que permitem a passagem de luz, mas de forma difusa. Ao atravessar um meio translúcido a luz se propaga de maneira irregular, o que também impossibilita que enxerguemos através dele. São exemplos de meios translúcidos: o papel manteiga e um vidro jateado. [6]

Nesse trabalho discutiremos a formação de cores por alguns mecanismos de interação da luz com diferentes materiais. É importante ressaltar que o conceito de cor vem da interpretação de sinais visuais por nosso cérebro. Ou seja, um feixe luminoso possui características físicas, como frequências e amplitudes de oscilação dos campos eletromagnéticos, mas não possui fundamentalmente uma cor, sendo esta uma interpretação do nosso cérebro à estimulação dos nossos olhos por esse feixe. Portanto, quando mencionamos a reflexão ou transmissão de uma cor, estamos nos referindo à reflexão ou transmissão da porção do espectro eletromagnético que produz a sensação visual referente àquela cor. Além disso, focamos nossas demonstrações em cores puras e primárias à visão humana: vermelho, verde e azul.[7]
Uma discussão mais profunda sobre os mecanismos físicos envolvidos na formação de cores, incluindo uma descrição mais completa sobre a interação da radiação com a matéria, foi apresentada por WEISSKOPF.[8]

\subsection{Cores em objetos opacos}

Os objetos opacos apresentam cor através da reflexão seletiva da luz. A luz branca que pode ser proveniente da luz do sol, por exemplo, é formada por todas as cores visíveis ou todas as cores do arco-íris. Ao incidir sobre um objeto vermelho, como a maçã mostrada na Fig. 1, apenas a cor vermelha é refletida, enquanto o restante das cores é absorvido pelo objeto. Os objetos são brancos quando refletem todas as cores, como é o caso da folha de papel ou de um pedaço de algodão. Por outro lado, se um objeto absorve todas as cores e, portanto, não reflete nenhuma delas, ele é visto como preto.

Além dos objetos brancos e pretos, na nossa vida cotidiana estamos cercados de objetos opacos de cor vermelha, azul, verde, entre outras cores. A título de ilustração, mostramos na Fig. 2 uma maçã vermelha, uma folha verde e um pássaro azul sendo iluminados com fontes de luz de diferentes cores. Quando iluminados com a luz branca (Fig. 2a), a maçã, a folha e o pássaro são vistos nas cores vermelha, verde e azul, respectivamente. No entanto, quando os objetos são iluminados com luz na cor vermelha (Fig. 2b), somente a maçã apresenta coloração vermelha, pois somente ela reflete a luz com essa cor. Nesse caso, os demais objetos aparentam ser pretos por não serem capazes de refletir luz vermelha. De forma análoga, vemos a folha verde e o pássaro azul quando a iluminação se dá nas cores verde (Fig. 2c) e azul (Fig. 2d), respectivamente, enquanto os outros objetos aparentam ser pretos.

\subsection{Cores em objetos transparentes}

Diferente dos objetos opacos, os objetos transparentes coloridos apresentam cor devido à transmissão seletiva

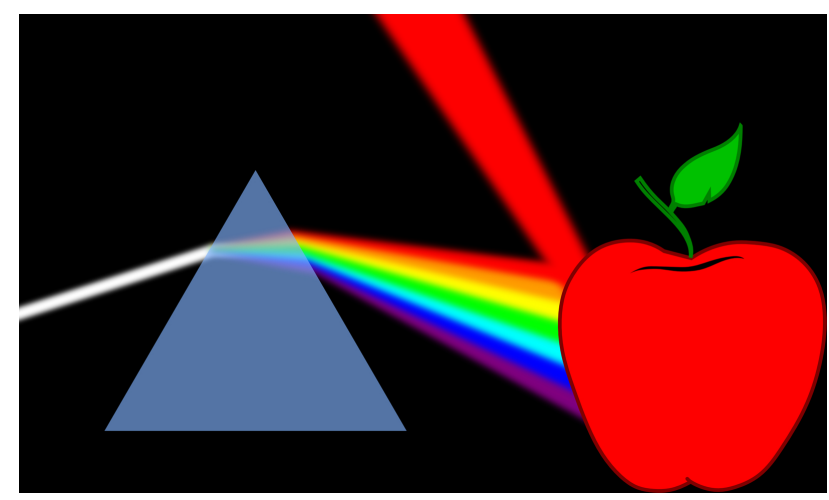

Figura 1: A reflexão seletiva da cor vermelha numa maçã ao ser iluminada por um feixe de luz branca. Ao atravessar um prisma, a luz branca se decompõe em diferentes cores, nos permitindo entender como as cores interagem com o objeto individualmente. 


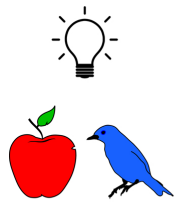

(a)

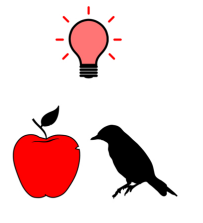

(b)

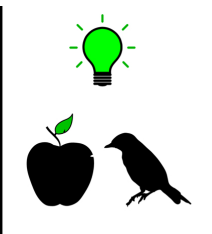

(c)

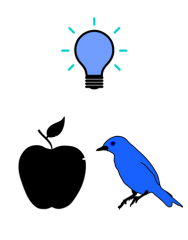

(d)
Figura 2: Objetos opacos coloridos apresentam sua cor devido à reflexão seletiva de luz. Quando iluminados por luz branca (a), composta por todas as cores, podemos observar as cores de todos os objetos. Quando está sob iluminação de uma cor que não é capaz de refletir, um objeto aparenta ser preto. Como exemplo, quando iluminados com luz vermelha (b), todos os objetos que não sejam vermelhos aparentam ser pretos. $\mathrm{O}$ mesmo acontece com as iluminações verde (c) e azul (d).

da luz. Um pedaço de vidro colorido contém pigmentos que absorvem certas cores e transmitem outras. Dessa forma, quando iluminada por uma fonte de luz branca, uma garrafa azul de vidro parece azul porque ela absorve todas as cores, exceto o azul, que ela transmite. Note que objetos podem assumir a mesma cor por mecanismos físicos diferentes. Assim como mostra a Fig. 3, a maçã é vermelha pois reflete seletivamente a cor vermelha enquanto a gelatina de morango é vermelha porque permite que apenas essa cor seja transmitida por ela.

\subsection{Objetos transparentes incolores}

Apesar da maioria dos objetos a nossa volta serem coloridos, muito dos objetos que enxergamos não detém nenhuma cor específica, ou seja, são incolores. Um dos exemplos mais comuns em nosso cotidiano é o de um copo de vidro cheio de água. Nossos olhos conseguem enxergar o copo de vidro, assim como também conseguem distinguir a água dentro do copo, ainda que ambos os objetos sejam transparentes e incolores. Isso se deve ao fato de que a luz, ao atravessar do meio ar para o meio vidro, ou para o meio água, tem sua trajetória desviada por conta da diferença da velocidade de propagação da luz nesses meios. Esse fenômeno é chamado de refração.[3]

Em um meio material uniforme, tal como o ar, a luz descreve uma trajetória retilínea, que é a forma mais rápida de se deslocar de um ponto a outro. No entanto,
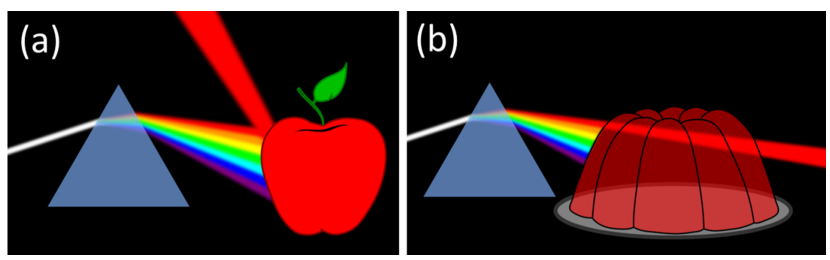

Figura 3: Comparação entre o processo de formação de cores em objetos opacos (a) e transparentes (b). Objetos opacos apresentam cores devido à reflexão seletiva de luz, enquanto objetos transparentes apresentam cores pela transmissão seletiva de luz. quando um raio luminoso passa de um meio para outro de forma oblíqua, ele tem sua trajetória desviada. Isso ocorre porque, devido ao fato de a velocidade da luz ser diferente em ambos os meios, a propagação em linha reta não representa a forma mais rápida de se deslocar de um ponto a outro, como estabelecido pelo princípio de Fermat.[9]

Como um exemplo desse fenômeno, podemos considerar um peixe dentro da água, como esquematizado na Fig. 4. Quando visto por um observador fora da água, há a impressão de que o peixe está em uma posição diferente da que ele de fato está devido à mudança da trajetória da luz ao passar pela interface entre água e ar.

Cada meio transparente permite que a luz se propague com uma velocidade definida em seu interior. A velocidade de propagação da luz no interior de um material transparente está intimamente ligada à capacidade deste material de desviar a luz. Na realidade, o desvio da luz depende de seu ângulo de incidência com a interface entre dois materiais e da razão entre as velocidades de propagação da luz nos dois meios que definem a interface. A grandeza física que quantifica a velocidade de propagação da luz em um meio, e está relacionada com a sua capacidade de desviar a luz, é o índice de refração.

O índice de refração do vidro é maior do que o da água, que é maior do que o do ar. Assim, a luz, ao atravessar do ar para vidro em ângulo oblíquo à interface, tem sua trajetória mais desviada do que se estivesse atravessando do ar para a água.

Um fenômeno interessante acontece quando dois meios apresentam valores de índice de refração muito próximos. Nesse caso, a luz sofre um desvio imperceptível ao atravessar a interface entre estes dois meios. Desta forma, os meios, por apresentarem características ópticas tão similares, não podem ser distinguidos visualmente. Ou seja, se um objeto sólido incolor é submerso em um

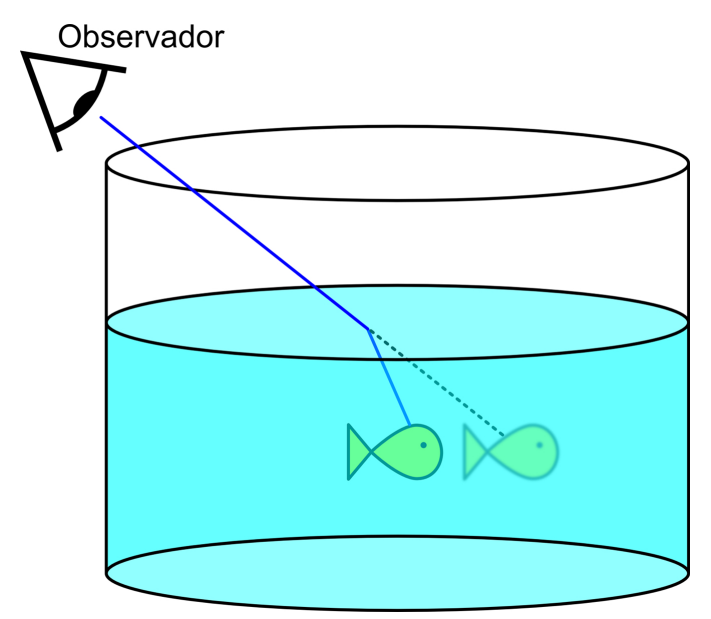

Figura 4: Objetos no interior de um tanque com água, quando observados em ângulo oblíquo por um observador localizado fora da água, podem aparentar estar em uma posição diferente daquela em que realmente se encontram devido ao desvio da luz na interface entre água e ar. 
meio líquido incolor com índice de refração coincidente com o seu, a impressão visual é de que o objeto sólido desaparece no interior do líquido.

\section{Descrição das Atividades}

O programa de atividades foi elaborado de forma a instigar a curiosidade dos alunos e estimulá-los a interagir durante o processo de aprendizagem. Para isso, ordenamos as atividades intercalando jogos com demonstrações práticas. Introduzimos os temas com jogos ou desafios para levantar questionamentos e, em seguida, explicamos os conceitos a partir de demonstrações, nas quais os alunos foram incentivados a participar. No total foram oito atividades, três para explicar o conceito de formação de cores por reflexão, três para formação de cores por transmissão e duas para o desvio de luz por objetos transparentes. O programa foi planejado para durar 30 minutos.

\subsection{Formação de cores por reflexão}

Para a primeira atividade, foram utilizados M\&Ms (pastilhas de chocolate coloridas) nas cores vermelho, verde e azul, copos plásticos e um LED vermelho. O LED vermelho faz parte de um sistema de LEDs de três cores (vermelho, verde e azul) utilizado ao longo da atividade.

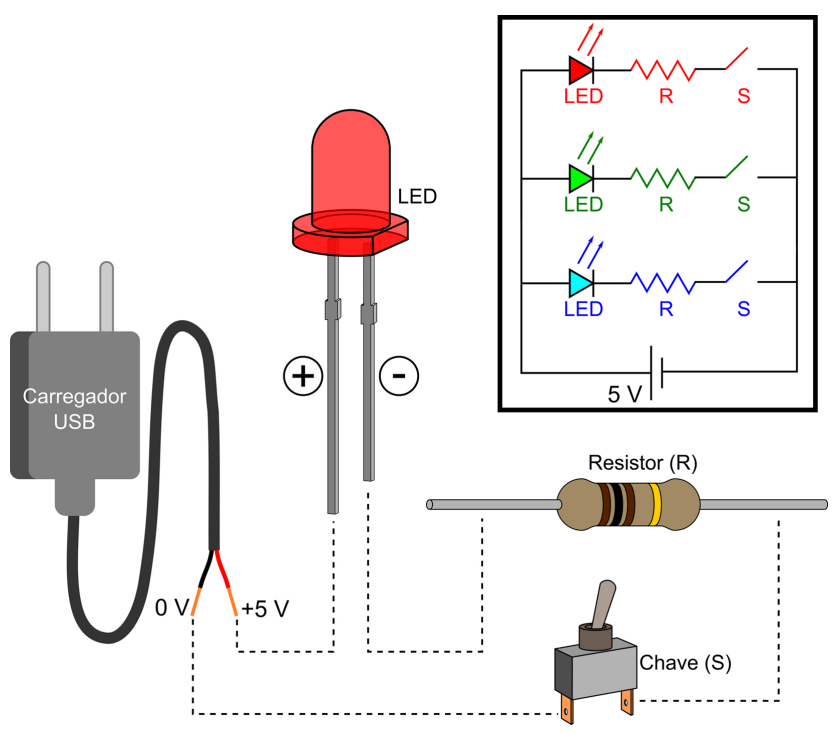

Figura 5: Uma fonte de $5 \mathrm{~V}$ (como por exemplo um carregador de celular) foi utilizada para fornecer energia elétrica ao circuito, que é composto de três linhas em paralelo. Cada linha é composta por um LED, um resistor e uma chave. O LED deve ser posicionado com seu lado negativo (identificado pelo terminal mais curto e por um chanfro na parte acrílica) voltado para a região negativa do circuito, conforme mostrado na figura. Os resistores, de aproximadamente $100 \Omega$, são utilizados para limitar a corrente no circuito e as chaves para permitir o desligamento individual de cada LED.
Seu esquema de montagem está esquematizado na Fig. 5 .

Com os M\&Ms já espalhados num recipiente sobre uma mesa, os alunos foram divididos em grupos de, no máximo, cinco pessoas. A cada grupo foi dado um copo plástico. Com a sala completamente escura, os M\&Ms foram iluminados pelo LED vermelho. Conforme explicado na seção anterior, a iluminação vermelha faz com que apenas os M\&Ms vermelhos se destaquem visualmente, enquanto os verdes e azuis aparentam ser pretos por não refletir a luz vermelha. A título de ilustração, na Fig. 6 mostramos o aspecto visual dos M\&Ms quando iluminados com luz branca e vermelha. Instruímos os grupos a coletarem $5 \mathrm{M} \& \mathrm{Ms}$, sendo que todos deveriam ser azuis. Seria declarado vencedor o grupo que tivesse coletado o maior número de M\&Ms azuis. Após a atividade, a luz branca da sala foi acesa novamente e os M\&Ms azuis coletados por cada grupo foram contados para que fosse definido o grupo vencedor. Então, os alunos foram questionados sobre a razão da dificuldade de identificar os M\&Ms azuis com a iluminação vermelha, a fim de iniciar uma discussão sobre a natureza das cores.

Em seguida, foi realizada uma demonstração prática para a qual distribuímos aos alunos quatro envelopes contendo uma palavra escrita em diferentes cores sobre um papel preto. Foram utilizados cartazes com palavras escritas em azul, verde e branco e a iluminação com LEDs nas cores vermelho, verde e azul. Para o papel preto, usamos folha sulfite preta e para as palavras em cor azul, verde e branco, utilizamos papel crepom, cartolina e papel sulfite, respectivamente. É importante que seja feito um teste com os LEDs para verificar a pureza de cor dos materiais escolhidos. Eles devem refletir somente a luz de sua cor e parecerem pretos quando iluminados com a luz das demais cores.

Para iniciar essa atividade, as luzes do ambiente foram apagadas. Cada aluno, para o qual foi entregue um envelope, revelava seu cartaz e o instrutor iluminava a palavra com os LEDs, um por vez, de modo que a palavra se revelasse somente na última tentativa, quando a cor do LED coincidisse com a cor da palavra. O objetivo dos estudantes nessa etapa foi o de adivinhar a cor da
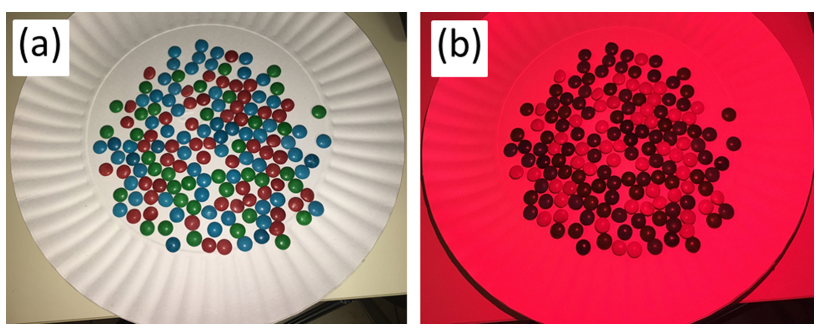

Figura 6: Aspecto visual dos M\&Ms espalhados sobre um prato de papel quando iluminados com (a) uma fonte de luz branca e (b) uma fonte de luz vermelha. Com a iluminação vermelha, os M\&Ms azuis e verdes aparentam ser pretos, criando dificuldade na sua identificação. 
palavra escrita. Por último, quando o envelope contendo a cor branca foi revelado, os estudantes foram desafiados a explicar porque a palavra sempre aparentava ter a mesma cor da iluminação. Após a demonstração, ficou evidente que cada objeto reflete unicamente a sua cor, sendo de fato essa a razão pela qual os objetos opacos apresentam cor.

A fim de ilustrar o conceito de composição de cores de uma forma acessível e interessante aos estudantes, construímos um disco de Newton, que é um disco colorido, contendo geralmente 7 cores, destinado a ser girado rapidamente de forma a produzir a sensação de soma das cores. O disco foi impresso e colado sobre um fidget spinner (brinquedo giratório). Ao girarmos o fidget spinner, o disco de Newton produz a sensação visual de ser branco (Fig. 7). O rolamento dos fidget spinners permite com que ele gire em alta velocidade por um período longo, sendo ideal para a realização desta demonstração. Para tornar a atividade mais participativa, pode-se ainda entregar para os alunos um material básico seguido de instruções para que eles preparem o seu próprio disco de Newton.

\subsection{Formação de cores por transmissão}

Para explicar a formação de cores por transmissão em objetos transparentes coloridos, com a luz do ambiente acesa, encostamos um pedaço de vidro vermelho em uma superfície preta fosca. Por não haver luz sendo transmitida pelo vidro, este aparenta ser preto. Ao ser afastado do fundo preto, permitindo assim com que a luz de fundo seja transmitida pelo objeto, o pedaço de vidro revela ter a cor vermelha. A Fig. 8a ilustra o aspecto visual do pedaço de vidro vermelho quando posicionado sobre os anteparos preto e branco. Através desse simples experimento, demonstra-se que objetos podem ter cor devido à transmissão seletiva de luz. Esse conceito é reforçado a partir da observação da transmissão da luz dos LEDs vermelho, verde e azul por esse vidro vermelho, conforme mostra a Fig. 8b. Posicionando-se o vidro vermelho entre os LEDs e um anteparo branco, observa-se que apenas a luz vermelha é transmitida por esse objeto. Esse re-

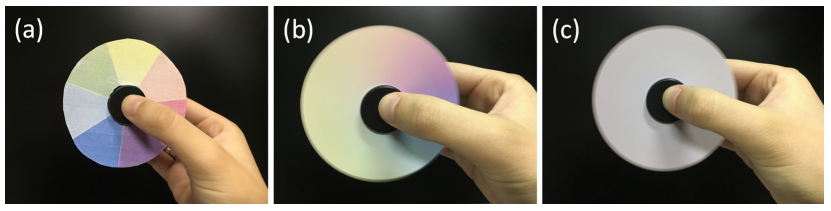

Figura 7: Disco de Newton montado sobre um fidget spinner parado (a), em baixa velocidade de rotação (b) e em alta velocidade de rotação (c). Podemos observar que conforme a velocidade do aparato aumenta, ocorre uma progressiva sensação visual de sobreposição das cores que compõe o disco até o limite em que o disco aparenta ser branco.
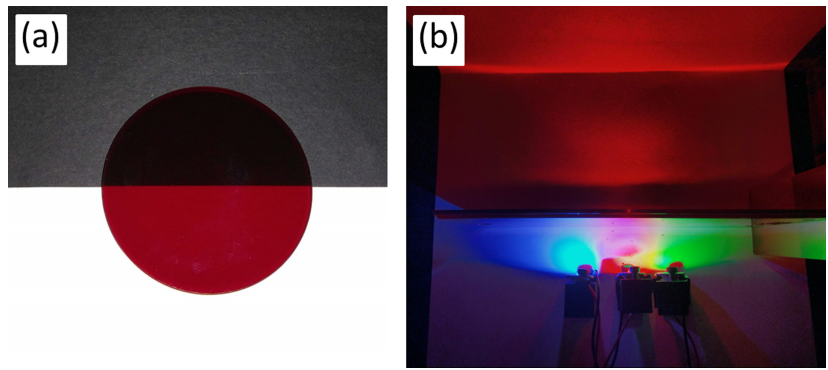

Figura 8: (a) Vidro colorido posicionado parcialmente sobre um fundo branco e um fundo preto. Como o fundo preto não reflete significativamente luz, não há luz atravessando o material na seção superior e portanto o vidro aparenta ser preto. Como o fundo branco reflete todas as cores e o vidro permite apenas a passagem da luz vermelha, ele aparenta ser vermelho na seção inferior. Desta forma, vemos que o vidro tem a cor vermelha apenas pela transmissão seletiva da cor vermelha, e não pela forma como reflete a luz. (b) Um objeto transparente de cor vermelha foi posicionado na frente de 3 LEDs de cor vermelha, azul e verde, mostrando que apenas a luz de cor vermelha é transmitida através do objeto e refletida pelo anteparo branco posicionado na parte superior da figura.

sultado mostra, portanto, que objetos dessa natureza transmitem exclusivamente a luz de sua cor.

A fim de concluir as demonstrações sobre formação de cores por transmissão, óculos com lentes coloridas na cor vermelha e óculos com lentes coloridas na cor azul (semelhantes a óculos 3D, mas com ambas as lentes de cores iguais) foram utilizados na observação de objetos vermelhos e azuis (objetos diferentes de cada cor) exibidos em um monitor LCD. Os óculos foram construídos utilizando uma armação plástica de baixo custo que pode ser encontrada em casas de festa e as lentes foram feitas com quatro camadas de papel celofane colorido. Distribuímos óculos com lentes vermelhas para metade dos alunos e óculos com lentes azuis para a outra metade. Essa atividade foi realizada com as luzes da sala acesas. Uma vez que todos estavam de óculos, exibimos uma imagem de fundo preto contendo a ilustração de uma estrela azul e de um coração vermelho no monitor, assim como é mostrado na Fig. 9a. Em seguida, perguntamos aos alunos o que eles estavam vendo na imagem. Como esperado, todos eles viram apenas um dos objetos, correspondente à cor de seus óculos. Dessa forma, mostramos que os óculos vermelhos permitem apenas a observação do objeto vermelho, enquanto que os óculos azuis per-
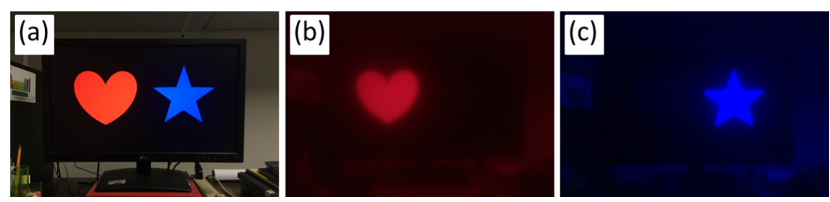

Figura 9: (a) Imagem exibida em um monitor LCD. (b) Mesma imagem quando observada através dos óculos com as lentes vermelhas e (c) através dos óculos de lentes azuis. 
mitem a observação apenas do objeto azul exibido no monitor (Fig. 9b-c). Após a atividade, realizamos uma discussão sobre a razão pela qual um dos objetos não pôde ser observado quando se usa os óculos, concluindo que estamos observando o mesmo princípio demonstrado com o experimento realizado com o vidro vermelho, ou seja, a formação de cores pela transmissão seletiva de luz.

\subsection{Refração e visualização de objetos incolores}

Até este momento as atividades realizadas com os estudantes tiveram o objetivo de demonstrar que os objetos podem refletir ou transmitir seletivamente a luz, o que permite que eles possuam cor. Além disso, objetos que refletem todas as cores se mostram brancos aos nossos olhos, assim como objetos pretos são aqueles que não refletem ou transmitem as cores visíveis.

Objetos incolores e transparentes, como o vidro de um copo, não possuem cor e, no entanto, ainda podemos observá-los. Dessa forma, a última parte do programa foi dedicada a mostrar como esses objetos incolores podem ser vistos devido a diferenças no índice de refração entre o objeto e o meio no qual ele está inserido.

Inicialmente foi apresentado aos alunos um copo cheio de água. Fica evidente que podemos ver a água, apesar de ela permitir a passagem de todas as cores de forma indistinta. Um lápis (ou qualquer objeto reto e opaco) é inserido na água, mostrando que ela deforma a imagem do objeto. Através dessa observação, é apresentada a propriedade do desvio dos raios luminosos - ou refração - por materiais com diferentes propriedades ópticas. O desvio dos raios luminosos faz com que a imagem de objetos situados atrás de um objeto transparente seja deformada. Essa deformação permite que detectemos o objeto transparente situado diante de nós.

Para concluir a atividade e demonstrar o fenômeno que ocorre quando um objeto transparente é inserido em um líquido com índice de refração muito próximo ao seu, inserimos um pedaço de acrílico num copo cheio de glicerina líquida. O acrílico e a glicerina possuem índices de refração muito próximos. O copo foi colocado na frente de um fundo preto e a parte de cima do copo foi coberta com fita adesiva, para que os estudantes não pudessem ver a parte do objeto de acrílico que flutua sobre a glicerina. Sob essas condições, ao observarem o copo cheio de glicerina, os estudantes conseguem perceber apenas que ele está cheio com um líquido, mas não percebem a presença do objeto acrílico. A presença da peça de acrílico só se torna evidente ao retirarmos ela de dentro da glicerina. Uma ilustração desse efeito é mostrada na Fig. 10.

\section{Considerações Finais}

Nesse trabalho elaboramos experimentos que demonstram conceitos importantes relacionados à formação de

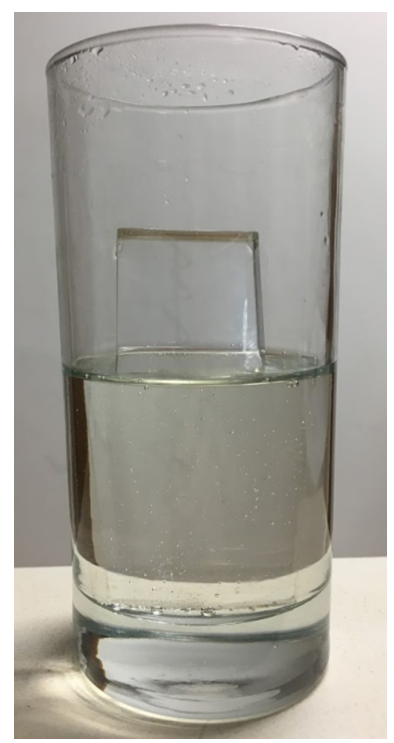

Figura 10: Quando inserido em material com índice de refração similar, um objeto transparente pode tornar-se visualmente imperceptível. Nesta imagem, uma placa de acrílico é parcialmente submersa em glicerina líquida, que tem um índice de refração muito próximo ao do acrílico. A parte submersa da placa de acrílico é praticamente imperceptível a olho nu, gerando a impressão de que o acrílico desaparece ou se dissolve quando submerso nesse material.

cores em objetos opacos e transparentes coloridos e à visualização de objetos transparentes incolores. Esses experimentos foram apresentados a aproximadamente 100 estudantes com idades variando entre oito e dezessete anos, com diferentes experiências e níveis de conhecimento acerca dos princípios básicos de óptica e de ciências em geral.

Com o intuito de intrigar os estudantes, as atividades foram elaboradas tendo em vista o impacto visual das observações. Além disso, os experimentos foram organizados de tal forma que apenas um conceito fundamental fosse trabalhado em cada etapa. Os estudantes foram expostos a demonstrações abertas, onde foram convidados a participar de jogos e atividades que ilustraram consequências notáveis da interação da luz com objetos de diferentes características. Eles também foram incentivados a propor hipóteses para explicar as observações realizadas durante as atividades.

Observamos que a abordagem utilizada foi capaz de manter o interesse e a atenção dos estudantes durante toda a extensão da apresentação. A realização e discussão de diferentes experimentos envolvendo conceitos similares permitiu a consolidação da compreensão dos princípios físicos envolvidos por parte dos estudantes, de forma que ao longo da atividade, os alunos eram capazes de propor explicações cada vez mais coerentes e corretas para as observações realizadas. 


\section{Contribuição dos autores}

Os autores F. R. Henrique, N. B. Tomazio e R. G. T. Rosa tem a mesma contribuição em primeira autoria pois ocupam posições de liderança no USP - IFSC OSA Student Chapter e portanto contribuíram mais ativamente para a concepção, gerenciamento e realização do trabalho. Os autores A. M. Souza, C. P. D'Almeida, L. F. Sciuti e M. R. Garcia, os quais compartilham a segunda autoria, contribuíram com ideias para a concepção do trabalho e com a sua realização. O autor L. De Boni, professor responsável pela supervisão das atividades realizadas pelo USP - IFSC OSA Student Chapter, contribuiu para a concepção e gerenciamentodo trabalho. Todos os autores contribuíram para a escrita e revisão do trabalho.

\section{Agradecimentos}

Gostaríamos de agradecer à equipe da escola de inglês The Four, de São Carlos - SP, pela disponibilidade do espaço e apoio durante a realização do evento de divulgação científica e ao Instituto de Física de São Carlos e ao Grupo de Fotônica pela infraestrutura disponibilizada para o desenvolvimento deste trabalho.

\section{Referências}

[1] J.L.P. Ribeiro e M. Verdeaux, Revista Brasileira de Ensino de Física 34, 4401 (2012).

[2] R.E.S Diniz, A pesquisa e o ensino de ciências: Relato de uma experiência. Ciência \& Educação 3, 25 (1996).

[3] L. Misoguti, C.R. Mendonça, A.M. Tuboy, R. Habesch e V.S. Bagnato, Revista Brasileira de Ensino de Física 19, 448 (1997).

[4] T.B. Borrajo e A.A. Coelho, Revista do Professor de Física 2, 23 (2018).

[5] G. Fourez, Alfabetización científica y tecnológica: Acerca de las finalidades de la enseñanza de las ciencias (Ediciones Colihue SRL, Buenos Aires, 1997).

[6] F. Ramalho Jr, N.G. Ferraro, e P.T. Soares, Os Fundamentos da Física vol. 2. (Moderna, São Paulo, 1996).

[7] H.J.A. Dartnall, J.K. Bowmaker e J.D. Mollon, Proc. R. Soc. Lond. B. 220, 115 (1983).

[8] V.F. Weisskopf, Scientific American 219, 60 (1968).

[9] P.G. Hewitt, Física Conceitual (Bookman, Porto Alegre, 2002). 